\title{
Dental Hygiene Education About Patients with Special Needs: A Survey of U.S. Programs
}

\author{
Maryam J. Dehaitem, B.S.; Karen Ridley, R.D.H., M.S.; Wendy E. Kerschbaum, \\ R.D.H., M.A., M.P.H.; Marita Rohr Inglehart, Dr. phil. habil.
}

Abstract: The objective of this study was to explore how dental hygiene programs in the United States educate their students about treating patients with special needs. Data were collected from 102 U.S. dental hygiene programs (response rate=49 percent) with a web-based survey. Nearly all programs (98 percent) reported that they present this material in lectures. However, only 42 percent of the programs required students to gain clinical experiences with patients with special needs. Most programs covered the treatment of patients with physical/sensory impairments such as hearing impairments ( 93.1 percent), psychopathologies (89.2 percent), and adult onset neurological disorders (89.2 percent). Outcome assessments were usually done in a written exam (97.1 percent), while objective structured clinical examinations (OSCEs) ( 9.8 percent) and standardized patient experiences (4.9 percent) were less frequently used. Respondents identified "curriculum overload" as the biggest challenge to addressing special patient needs. Nevertheless, 29.4 percent of the respondents indicated that they support an increase in clinical experiences for students to give them increased opportunities to work with patients with special needs. Recent changes in accreditation standards require graduating dental hygiene students to be competent in assessing the treatment needs of special needs patients. Based on the program directors' responses, recommendations can be made to increase the opportunities for students to have clinical experiences with patients with special needs and to address the needs of patients with special needs more comprehensively in dental hygiene curricula.

Ms. Dehaitem is a dental hygiene graduate student, Department of Periodontics and Oral Medicine, School of Dentistry; Prof. Ridley is Assistant Professor of Dental Hygiene, Department of Periodontics and Oral Medicine, School of Dentistry; Prof. Kerschbaum is Director, Dental Hygiene Program and Associate Professor of Dental Hygiene, Department of Periodontics and Oral Medicine, School of Dentistry; and Dr. Inglehart is Associate Professor, Department of Periodontics and Oral Medicine, School of Dentistry and Adjunct Associate Professor, Department of Psychology, College of Literature, Science, and Artsall at the University of Michigan. Direct correspondence and requests for reprints to Dr. Marita Rohr Inglehart, Department of Periodontics and Oral Medicine, School of Dentistry, University of Michigan, 1011 North University Avenue, Ann Arbor, MI 48109-1078; 734-763-8073 phone; 734-763-5503 fax; mri@umich.edu.

Key words: dental hygiene education, dental hygiene curriculum, dental hygiene programs, patients with special needs, medically compromised patients, access to care

Submitted for publication 12/12/07; accepted 4/29/08

$\mathrm{T}$ The number of people with special needs in the United States is steadily increasing. The 2000 U.S. census found that about 50 million people had a long-standing condition or disability, which means that 19.3 percent of the U.S. population had one disability or more. In addition, more than 43 million U.S. citizens were severely disabled and needed assistance in various ways such as by being reliant on crutches or a wheelchair, having a mental or emotional condition that interfered with their independent functioning, or receiving federal benefits due to their inability to work. ${ }^{1}$

In 2000, the first-ever U.S. surgeon general's report on oral health ${ }^{2}$ alerted dental and dental hygiene educators to the fact that patients with special needs have disproportionate amounts of oral disease and problems with access to oral health care services.
Other research findings supported this conclusion. ${ }^{3,4}$ Considering the disproportionate burden of oral health for patients with special needs and their access to care problems, it seems important to reflect on the role of dental and dental hygiene education in preparing future practitioners for the treatment of this patient population. Dao et al. ${ }^{5}$ found that the more dentists agreed with statements that their dental education had prepared them well to treat patients with special needs, the more likely they were to actually treat these patients and to have staff members who were comfortable and knowledgeable when providing care for them. Dao et al. provided an overview of the research concerning educational efforts in this area. They described research that indicated that patients with special needs were being neglected in dental and dental hygiene curricula. However, they also reported 
research such as the study by Kinne and Stiefel ${ }^{6}$ that supported the hypothesis that the majority of dental students will treat patients with special needs if they feel capable of treating these patients. Stoltenberg and Walker ${ }^{7}$ found that attitudes of dental hygienists towards patients with special needs were more influenced by concrete clinical experiences with patients rather than by formal coursework, indicating that formal classroom-based instruction needs to be accompanied by actual clinical training.

In 1990, Bickley ${ }^{8}$ reported that dental hygienists' concerns about the treatment of patients with special needs were related to the type of handicap. Dental hygienists were not so much concerned about actually carrying out the treatment, but more with the perceived uncertainty of behavioral and communication difficulties while treating these patients. This finding indicated that dental hygienists' concerns might be largely related to a lack of understanding how certain disabilities might affect their interactions with the patients. This study found that 73.5 percent of the dental hygienists surveyed felt that their training concerning their role in treating mentally handicapped patients had been inadequate.

Given these findings, it is encouraging that, on July 30, 2004, the Commission on Dental Accreditation adopted a revision of dental hygiene Standard $2-18$, which added a competency concerning the assessment of treatment needs of patients with special needs. On January 1, 2006, this adopted revision of Standard 2-18 ${ }^{9}$ was implemented; it states that "Graduates must be competent in assessing the treatment needs of patients with special needs." In addition, the intent statement in the standards states that "Clinical instruction and experiences with the patients with special needs should include instruction in proper communication techniques and assessing the treatment needs compatible with the special need."

One interesting question is how dental hygiene programs in the United States have addressed this standard. The objective of this study, therefore, was to assess the curricular experiences provided to students in U.S. dental hygiene programs related to the treatment of patients with special needs. Specifically, this study examined a) which specific special needs are addressed in dental hygiene curricula, b) how students are educated about these issues, c) who provides education about patients with special needs, and d) how dental hygiene administrators evaluate their present educational efforts and future potential changes in their curricula related to patients with special needs.

\section{Methods}

This study was approved by the Institutional Review Board for the Health Sciences at the University of Michigan (IRB-Health \# HUM00004026).

Between November 2006 and January 2007, an email was sent to 240 directors of dental hygiene programs in the United States. The email addresses of these program directors were obtained from the website of the American Dental Hygienists' Association (ADHA). Thirty emails were returned as undeliverable. From the 210 dental hygiene directors who received the email, 102 submitted completed surveys, for a response rate of 49 percent. The respondents reported that their programs were situated at different types of institutions such as community or junior colleges, universities or four-year colleges, technical colleges, and dental schools.

After a draft of a survey had been designed by the investigators, a pilot test of this survey was conducted with eight dental hygiene program directors. These program directors had been identified in a literature search for peer-reviewed articles reporting survey-based research by dental hygiene program directors. These eight individuals received an email with the request to provide feedback to the draft survey during the two weeks after they received the email. All eight program directors returned the survey with feedback concerning the content and presentation of the questions. This feedback was used to revise the survey and develop the final version of the questionnaire. This questionnaire was then placed on a website provided by the UMLessons Program, an online system operated by the Information Technology Division at the University of Michigan for collecting web-based survey data.

An email was then sent to all dental hygiene program directors whose addresses were posted on the ADHA website, asking them to respond to the web-based survey that they could access through a web link. Two follow-up emails were sent three and six weeks later. The website was closed in the middle of January 2007.

The web-based material consisted of an introduction to the survey and the actual survey. The introduction explained the purpose of the survey, assured the respondents that their responses would be anonymous, and said they would receive information about the results if they wanted such information.

The survey consisted of twenty-four questions. Questions 1 to 3 were concerned with a general de- 
scription of the program, especially its location, the type of degree given, the average number of students graduating per year, and the number of years students were enrolled. Questions 4 to 16 asked about the curricular efforts concerning patients with special needs. These questions addressed which groups of patients with special needs were included in the educational efforts, when the students received education about patients with special needs, who provided this information, how much training the students received, in which educational settings the students received this training, how the outcomes were assessed, and which teaching materials were used.

The remaining questions asked the respondents about their evaluation of the educational experiences their students received about this topic, any future changes they were considering for their programs, and their satisfaction with the way their students were educated about treating patients with special needs. Two open-ended questions completed the survey. These questions asked the respondents to list all resources that they used in their educational efforts about patients with special needs and to share any additional comments about the survey.

The UMLessons program collects online survey data in the form of an Excel file. This file was imported into SPSS (Version 14.0). ${ }^{10}$ Descriptive statistics (e.g., frequency distributions, means, standard deviations, ranges) were used to present an overview of the findings, and inferential statistics showed whether relationships between variables and group differences were significant.

\section{Results}

Of the 102 respondents, fifty-eight (56.9 percent) directed programs at community or junior colleges, sixteen (15.7 percent) at universities or four-year colleges, twelve (11.8 percent) at technical colleges, seven (6.9 percent) at schools of allied health sciences, six (5.9 percent) at dental schools, and only one respondent (1.0 percent) directed a program at a separate department at a dental school. Eighty-six programs ( 84.3 percent) were associate degree programs, with 20.6 percent awarding baccalaureate degrees and 3.9 percent diplomas/certificates. The number of students per year in the programs ranged from eleven to sixty students (mean $=25.14$; $\mathrm{SD}=10.514$ ). While the majority of the programs (89.2 percent) were two years long, 8.8 percent were three years long, and only 1.0 percent were four years long. (In this paragraph, numbers do not add up to 102 and percents do not add up to 100 percent because of different response rates for the questions.)

\section{Special Needs Addressed in the Dental Hygiene Curricula}

The first objective was to determine how many dental hygiene programs include material concerning the treatment of patients with special needs within their curricula and, more specifically, which types of special needs are covered in these educational efforts. While all programs include these materials in one way or another, not all dental hygiene programs require students to provide clinical care for patients with special needs. Forty-three programs (42 percent) responded that their students are required to treat patients with special needs, while fifty-eight programs (56.9 percent) did not have such a requirement for their students (one did not respond).

As shown in Table 1, most programs reported that they have curricula that expose their students to the treatment of patients with various forms of more prevalent physical/sensory impairments such as hearing impairments (93.1 percent), psychopathologies (89.2 percent), adult onset neurological disorders (89.2 percent), visual impairments (88.2 percent), and motion impairments ( 88.2 percent) (see Table 1). In addition, more than eight out of ten programs address issues such as addictions ( 87.3 percent), Down syndrome ( 86.3 percent), Alzheimer's disease ( 85.3 percent), cerebral palsy ( 84.3 percent), and developmental delays (80.4 percent). Autism and ADHD are addressed by approximately seven out of ten programs, while fetal alcohol syndrome (FAS) (53.9 percent) and closed head injuries (44.1 percent) are addressed even less frequently.

Sixteen respondents offered answers to openended questions concerning other types of special needs that their programs address. These answers fell into four categories: medically compromised patients, patients with physical impairments, patients with mental illness, and patients from specific sociodemographic groups. Medically compromised patients included those with cardiac disease and autoimmune diseases (four responses each), diabetes (two responses), and epilepsy, cancer, blood disorders, and Sjögren's syndrome (one response each). Physical impairments mentioned were scleroderma and stroke with two responses each, as well as spina bifida, spinal cord injuries, lupus, osteoarthritis, and rheumatoid arthritis. Four respondents mentioned 
mental health issues, namely, eating disorders (two responses), patients with fear, and patients who abuse drugs. Under the category of sociodemographic features, three respondents mentioned elderly or geriatric patients as a special group of patients they address in coursework, and one respondent each mentioned children and women/gender-related issues.

In addition to exploring which specific types of issues were addressed in the different programs, the respondents were also asked to indicate on a scale from $1=$ lowest priority to $5=$ highest priority how much of a priority teaching about patients with special needs was in their programs. No respondents indicated that the subject of patients with special needs had the lowest or second lowest priority. However, eight respondents indicated an average level of priority ( 7.8 percent), while fifty-five participants responded with an answer of 4 , which is the second to the highest level of priority (53.9 percent), and thirty-seven programs (36.3 percent) indicated that this topic had the highest priority in their curriculum. (Two respondents did not answer this question.)

\section{How Students Are Educated About Special Needs Patients}

In addition to assessing whether the programs included in their curricula different types of subject matter pertinent to patients with special needs, the question of how curriculum coverage was provided was explored. To investigate the educational methods used, the respondents answered the following questions:

- Who instructs the students?

- Which specific aspects of clinical interactions with patients with special needs are addressed in the curriculum?

- How is the material taught (such as in classroom settings, clinics, or community-based external rotations and in lectures or case presentations)?

- When is this material introduced and discussed with the students?

- How are educational outcomes/competencies assessed? and

- Which resources are used when teaching about this topic?
Table 2 provides an overview concerning the question of who teaches dental hygiene students about the treatment of patients with special needs. Dental hygienists were said to be the primary instructors in these educational efforts (78.4 percent). In addition, 41.2 percent of the respondents mentioned that dental hygienists with specialty training in the treatment of patients with special needs are involved in these educational efforts. Fifty-six programs (55 percent) reported that two different types of instructors (see Table 2 for the different instructors involved) or even more are involved in the teaching of these issues. This fact suggests that, in many programs, an interdisciplinary approach to teaching this subject matter is taken. Overall, it was apparent that educators with a wide range of experiences and from very different backgrounds are involved in these educational efforts.

Table 3 provides an overview concerning which specific issues are presented when discussing providing care for different groups of patients with special needs. All but one program covers communication issues pertinent to treating patients with special needs (99 percent) and the oral manifestations of 


\begin{tabular}{lcc}
$\begin{array}{l}\text { Table 2. Types of instructors involved in these educational efforts* } \\
\text { Type of Instructor }\end{array}$ & Prequency & Percentage \\
\hline $\begin{array}{lcc}\text { Dental hygienist } & 80 & 78.4 \% \\
\begin{array}{l}\text { Dental hygienist with training in the } \\
\text { treatment of patients with special needs }\end{array} & 42 & 41.2 \% \\
\begin{array}{l}\text { Dentist with training in the treatment of } \\
\text { patients with special needs }\end{array} & 18 & 17.6 \% \\
\text { General dentist } & 13 & 12.7 \% \\
\text { Pediatric dentist } & 13 & 12.7 \% \\
\text { Nurse } & 9 & 8.8 \% \\
\text { Teacher } & 8 & 7.8 \% \\
\text { Behavioral scientist } & 8 & 7.8 \% \\
\text { Oral and maxillofacial surgeon } & 3 & 2.9 \% \\
\text { Geriatric dentist } & 2 & 2 \% \\
\text { Physician } & 1 & 1 \% \\
\text { Other qualifications } & 8 & 7.8 \%\end{array}$
\end{tabular}

*The wording of this question was as follows: "Which professional training do(es) the faculty member(s) have who teach(es) students about the topic of treating patients with special needs?"

various patients with special needs ( 99 percent). In addition, all but two programs ( 98 percent) address patient management concerns and how to provide instructions for parents and caregivers. More than 90 percent of the programs indicated that they pro-

\section{Table 3. Frequencies/percentages with which specific issues are ad- dressed when teaching about the treatment of patients with special needs*}

\begin{tabular}{lcc} 
Separate Components & Frequency & Percentage \\
\hline Communication & 101 & $99.0 \%$ \\
Oral manifestations & 101 & $99.0 \%$ \\
Patient management & 100 & $98.0 \%$ \\
Instructions to parents and caregivers & 100 & $98.0 \%$ \\
Oral disease prevention & 96 & $94.1 \%$ \\
Appointment scheduling & 94 & $92.2 \%$ \\
Behavioral management & 94 & $92.2 \%$ \\
Wheelchair transfer & 92 & $90.2 \%$ \\
Fluorides & 92 & $90.2 \%$ \\
Ethical issues & 92 & $90.2 \%$ \\
Legal issues & 85 & $83.3 \%$ \\
Barrier-free environments & 84 & $82.4 \%$ \\
Patient reception & 83 & $81.4 \%$ \\
Instrumentation & 80 & $78.4 \%$ \\
Diet counseling & 80 & $78.4 \%$ \\
Tobacco cessation & 76 & $74.5 \%$
\end{tabular}

*The wording of this question was as follows: "Think about the separate components of patient-provider interactions. Which of these components are addressed in your education about the treatment of patients with special needs? (Check all that apply.)" vide instruction related to oral disease prevention (94.1 percent), appointment scheduling ( 92.2 percent), behavioral management (92.2 percent), wheelchair transfer ( 90.2 percent), fluorides ( 90.2 percent), and ethical issues (90.2 percent). In addition, more than 80 percent of the responding dental hygiene programs address legal issues ( 83.3 percent), barrier-free environments (82.4 percent), and patient reception ( 81.4 percent). Instrumentation and diet counseling are addressed by 78.4 percent of the programs and tobacco cessation by 74.5 percent of the programs. Only one respondent described an additional aspect, which was "treatment plan modifications relative to the various special needs and whether or not special facilities are necessary for treatment, i.e., if hospitalization is required for whatever reason."

Concerning how the material is taught, a first question in this section of the survey asked whether the programs taught this material in a required course within the dental hygiene curriculum, as part of another dental hygiene course, in occasional lectures in other courses, or in any other ways. Fifty percent of the programs indicated that they teach this material as a required course. Course titles include "Special Needs Patients" $(\mathrm{N}=12)$ and "Medically Compromised Patients" ( $\mathrm{N}=4)$. In addition, 43.1 percent of the respondents indicated that they teach this material as part of a dental hygiene course, and 5.9 percent as occasional lectures in several other courses.

The respondents were also asked to indicate which methods are used to present the material. Nearly all programs ( 98 percent) use lectures, and 83.3 percent of the programs also use case studies. The use of videotapes/DVDs was also frequently reported (62.7 percent), followed by demonstrations (53 percent). Fifteen respondents provided open-ended responses and identified other teaching/learning methods such as student presentations (eight responses), specific enrichment programs in community settings (five responses), and creating summaries of articles (one response). 
Table 4 provides an overview of how many hours of education are offered in different settings. The respondents reported averages of 35 hours in clinical settings, 23.6 hours in classroom settings, 18.6 hours in external clinical settings, and approximately 12 hours in community settings. However, the curriculum hours devoted to patients with special needs range from a minimum of very few hours in each setting (namely, 2, 3, or 3.5 hours) to a maximum of very high numbers of hours.

Next, respondents were asked to indicate when special needs topics are presented in the overall context of the curriculum. Over half of the programs introduce their students to the topic of treating patients with special needs during their first year of the program (52 percent), while the rest of the programs reported that they introduce this topic during the second year. These percentages add up to over 100 percent because some programs gave two answers, presumably because they listed all years in which they cover this topic.

Concerning the assessment methods used to evaluate the students' competency in the care of patients with special needs, 97.1 percent of the respondents indicated that they use written exams, 87.3 percent use evaluations of the students' management of patients, and 77.5 percent utilize student analysis of case studies as a method of assessment. Only 9.8 percent of the programs use objective structured clinical examinations (OSCEs), and less than 5 percent reported using standardized patient interactions for outcome assessment purposes. Nine respondents contributed answers to the open-ended questions about assessment methods, mentioning, for example, that they assess outcomes by having their students make oral presentations (three responses) or evaluating the students' clinical performance (three responses).

Respondents were also asked to provide an assessment of their students' level of competence concerning the management of patients with special needs at the time of graduation on a scale from $1=$ not at all competent to $5=$ highly competent. Over twothirds of the programs evaluated their students as either "fairly competent" (45.1 percent) or as "highly competent" (22.5 percent), and only thirty programs (29.4 percent) ranked their students as "somewhat competent," with one program (1 percent) describing its students as "not very competent." (Not all respondents answered this question.)

The answers to the question concerning the resources used when teaching about treating special needs individuals revealed that most programs (94.1
Table 4. Average number of hours of instruction in different settings*

\begin{tabular}{lcc} 
Setting & Mean & SD/Range \\
\hline Classroom setting & 23.56 & $59.44 / 2$ to 70 \\
Clinical setting & 35.17 & $59.44 / 3$ to 420 \\
External clinical setting & 18.56 & $14.55 / 3.5$ to 64 \\
Community setting & 11.96 & $10.38 / 2$ to 48
\end{tabular}

*The wording of this question was as follows: "How many hours are spent in classroom-based classes, in clinics, and in external rotations and community settings on the topic of treating patients with special needs?"

percent) use textbooks as the first resource, while peer-reviewed journals are used by 84.3 percent of the programs. Less than 70 percent of the programs reported that they use websites and audiovisual materials ( 68 percent), and 26.5 percent use magazines and newspapers as a teaching resource. Eight programs offered open-ended responses and mentioned other teaching resources such as student presentations (two programs).

\section{Perceived Challenges, Expected Changes, and Satisfaction with the Special Needs Curriculum}

While it is interesting to assess how dental hygiene programs cover this material, it seems also worthwhile to explore the respondents' overall perceptions and attitudes concerning this topic area. As shown in Table 5, a first question assessed the perceived challenges when teaching about these issues. On average, the respondents do not think that there is a lack of faculty expertise to teach about this topic (on a five-point scale from $1=$ not at all a problem: 1.85) or a lack of educational resources (mean=2.11). However, they agree more strongly that curriculum overload might impact the degree to which they could include material about this topic (mean=3.12). Clinical issues such as a lack of patients and a lack of clinical sites were rated as rather less important concerns (means $=2.39$ and 2.45 , respectively). In addition to considering the average responses to this question, it is also interesting to look at the range of answers to these five questions. The answers to the question concerning the curriculum overload were very evenly distributed over all five points of the answer scale. These findings clearly indicate that dental hygiene programs differ quite substantially in their available 


\begin{tabular}{|c|c|c|c|c|c|c|}
\hline Challenge & $\begin{array}{c}1 \\
=\text { not at all }\end{array}$ & 2 & 3 & 4 & $\begin{array}{c}5 \\
=\text { very much }\end{array}$ & $\begin{array}{c}\text { Mean } \\
(\mathrm{SD})\end{array}$ \\
\hline Lack of faculty expertise & $\begin{array}{c}51 \\
50 \%\end{array}$ & $\begin{array}{c}25 \\
24.5 \%\end{array}$ & $\begin{array}{c}15 \\
14.7 \%\end{array}$ & $\begin{array}{c}9 \\
8.8 \%\end{array}$ & $\begin{array}{c}1 \\
1.0 \%\end{array}$ & $\begin{array}{c}1.85 \\
(1.043)\end{array}$ \\
\hline Lack of clinical sites & $\begin{array}{c}34 \\
33.3 \%\end{array}$ & $\begin{array}{c}23 \\
22.5 \%\end{array}$ & $\begin{array}{c}14 \\
13.7 \%\end{array}$ & $\begin{array}{c}22 \\
21.6 \%\end{array}$ & $\begin{array}{c}7 \\
6.9 \%\end{array}$ & $\begin{array}{c}2.45 \\
(1.344)\end{array}$ \\
\hline Lack of patients & $\begin{array}{c}35 \\
34.3 \%\end{array}$ & $\begin{array}{c}24 \\
23.5 \%\end{array}$ & $\begin{array}{c}16 \\
15.7 \%\end{array}$ & $\begin{array}{c}17 \\
16.7 \%\end{array}$ & $\begin{array}{c}8 \\
7.8 \%\end{array}$ & $\begin{array}{c}2.39 \\
(1.333)\end{array}$ \\
\hline Lack of educational resources & $\begin{array}{c}37 \\
36.3 \%\end{array}$ & $\begin{array}{c}27 \\
26.5 \%\end{array}$ & $\begin{array}{c}27 \\
26.5 \%\end{array}$ & $\begin{array}{c}9 \\
8.8 \%\end{array}$ & $\begin{array}{c}1 \\
1.0 \%\end{array}$ & $\begin{array}{c}2.11 \\
(1.038)\end{array}$ \\
\hline Curriculum overload & $\begin{array}{c}19 \\
18.6 \%\end{array}$ & $\begin{array}{c}18 \\
17.6 \%\end{array}$ & $\begin{array}{c}16 \\
15.7 \%\end{array}$ & $\begin{array}{c}24 \\
23.5 \%\end{array}$ & $\begin{array}{c}22 \\
21.6 \%\end{array}$ & $\begin{array}{c}3.12 \\
(1.445)\end{array}$ \\
\hline
\end{tabular}

*The wording of this question was as follows: "How much does each of the following serve as a barrier to the education of your students about the treatment of special needs patients?"

Note: Percentages may not total $100 \%$ because of rounding.

resources for their educational efforts concerning the treatment of patients with special needs.

Given these differences in the perceptions of challenges encountered when teaching about these issues, it is also interesting to look at the findings concerning the respondents' satisfaction concerning their educational efforts (see Table 6). The respondents were asked to rate their satisfaction with six different aspects of their program's efforts on a scale from $1=$ very dissatisfied to $5=$ very satisfied. On average, the respondents are quite satisfied with their students' classroom experiences (mean=4.25). Only two programs said they were either very dissatisfied or dissatisfied, and only seven programs were neutral in their satisfaction with this issue. A similarly high level of satisfaction was reported concerning the average satisfaction with the faculty (mean=4.06). While satisfaction with the students' clinical experience (mean $=3.79)$, teaching resources (mean $=3.77$ ), and extramural experience $($ mean $=3.74)$ was still rather positive, satisfaction with the patient pool was relatively the lowest (mean $=3.53$ ).

Given this rather high level of satisfaction and the relative lack of perceived challenges, it is interesting to see whether the different respondents plan any changes in the coverage of this topic in their curricula. The respondents were therefore asked whether they anticipate any of six listed changes or any other changes that they could report with an open-ended response. The six listed changes were to

Table 6. Respondents' satisfaction with different aspects of their educational efforts*

\begin{tabular}{|c|c|c|c|c|c|c|}
\hline & $\begin{array}{c}1 \\
=\text { very dissatisfied }\end{array}$ & 2 & 3 & 4 & $\begin{array}{c}5 \\
=\text { very satisfied }\end{array}$ & $\begin{array}{l}\text { Mean } \\
(\mathrm{SD})\end{array}$ \\
\hline Classroom experience & $\begin{array}{c}1 \\
1.0 \%\end{array}$ & $\begin{array}{c}1 \\
1.0 \%\end{array}$ & $\begin{array}{c}7 \\
6.9 \%\end{array}$ & $\begin{array}{c}54 \\
52.9 \%\end{array}$ & $\begin{array}{c}37 \\
36.3 \%\end{array}$ & $\begin{array}{l}4.25 \\
(.716)\end{array}$ \\
\hline Clinical experience & $1.0 \%$ & $\begin{array}{c}14 \\
13.7 \%\end{array}$ & $\begin{array}{c}12 \\
11.8 \%\end{array}$ & $\begin{array}{c}51 \\
50.0 \%\end{array}$ & $\begin{array}{c}22 \\
21.6 \%\end{array}$ & $\begin{array}{c}3.79 \\
(.977)\end{array}$ \\
\hline Extramural experience & $2.9 \%$ & $\begin{array}{l}4 \\
3.9 \%\end{array}$ & $\begin{array}{c}29 \\
28.4 \%\end{array}$ & $\begin{array}{c}36 \\
35.3 \%\end{array}$ & $\begin{array}{c}22 \\
21.6 \%\end{array}$ & $\begin{array}{c}3.74 \\
(.972)\end{array}$ \\
\hline Faculty experience & $\begin{array}{c}1 \\
1.0 \%\end{array}$ & $2.9 \%$ & $\begin{array}{c}12 \\
11.8 \%\end{array}$ & $\begin{array}{c}56 \\
54.9 \%\end{array}$ & $\begin{array}{c}27 \\
26.5 \%\end{array}$ & $\begin{array}{c}4.06 \\
(.780)\end{array}$ \\
\hline Patient pool & $2.0 \%$ & $\begin{array}{c}23 \\
22.5 \%\end{array}$ & $\begin{array}{c}13 \\
12.7 \%\end{array}$ & $\begin{array}{c}44 \\
43.1 \%\end{array}$ & $\begin{array}{c}18 \\
17.6 \%\end{array}$ & $\begin{array}{c}3.53 \\
(1.096)\end{array}$ \\
\hline Teaching resources & $\begin{array}{c}1 \\
1.0 \%\end{array}$ & $\begin{array}{c}13 \\
12.7 \%\end{array}$ & $\begin{array}{c}15 \\
14.7 \%\end{array}$ & $\begin{array}{c}44 \\
43.1 \%\end{array}$ & $\begin{array}{c}21 \\
20.6 \%\end{array}$ & $\begin{array}{c}3.77 \\
(.962)\end{array}$ \\
\hline
\end{tabular}

*The wording of this question was as follows: "On a scale from $1=$ very dissatisfied to $5=$ very satisfied, how satisfied are you with the following aspects of your program's education concerning the treatment of special needs patients?"

Note: Percentages may not total $100 \%$ because of rounding. 
"increase clinical experience," "increase extramural experience," "increase classroom time," "decrease classroom time," "decrease clinical experience," and "decrease extramural experience." A total of 16.7 percent of the respondents thought that they would increase the classroom time for this topic, 29.4 percent that they would increase the clinical experiences, and 24.5 percent the extramural experiences. Not one program responded that they anticipate a decrease in the time spent on these issues.

\section{Differences Among Programs in Coverage of These Topics}

One interesting additional question could be whether dental hygiene programs differ in their coverage of these topics. A first consideration could be whether the length of the programs affects the degree to which these issues are covered. The dental hygiene programs that responded to this question were divided into two groups according to the length of the program - namely, two-year (89.2 percent) versus threeand four-year programs (9.9 percent). A multivariate analysis of variance with the independent variable "program length" and the four dependent variables "number of hours spent learning about these matters in classrooms," "clinics," "external settings," and "community settings" found that the main effect was not significant. The two-year programs did not differ on average from the three/four-year programs in the number of hours spent learning about patients with special needs in classrooms, clinics, external settings, and community settings. An additional multivariate analysis with the dependent variables "satisfaction with their students' classroom experiences," "clinical experiences," "extramural experiences," "faculty expertise," "patient pool," and "teaching resources" also found no significant difference between the average responses of the two- and the three/four-year programs. In addition, an independent sample t-test found that the program directors of the two-year programs did not differ in their average perceptions of the competency of their graduating students from the program directors of the three/four-year programs.

The second consideration is concerned with differences among programs with smaller or larger numbers of students. The programs were therefore divided into two groups according to the number of students admitted per year. The directors of programs with less than twenty-five students did not differ from the directors of programs with twenty-five or more students in their average satisfaction scores. The only significant difference found was that directors of smaller programs were less satisfied than directors of larger programs with extramural experiences for their students.

\section{Discussion}

Given the high percentage of children and adults in the United States with disabilities and special needs ${ }^{1}$ and considering their substantial need for access to dental care, ${ }^{2}$ it seems crucial to prepare all future dental practitioners in such a way that they can assess the treatment need of patients with special needs and be able to provide basic care. The changes in the accreditation standards ${ }^{9}$ are evidence of this recognition and provide a basis to assess whether dental hygiene programs meet this standard. A large percentage of graduating dental students in 2006 reported that they were not well prepared to treat patients with disabilities; only 6.2 percent reported they felt well prepared in this area. ${ }^{11}$ No comparable data are available from dental hygiene students because they do not respond to an annual survey when they graduate from their programs. This study therefore collected data from dental hygiene program administrators concerning how well their programs address this area of patient care in their curricula. The results showed that all responding programs include these issues in their curricula.

The interpretation of the findings has to consider that these data were collected from the dental hygiene program directors about their own programs and the quality of their own graduating students. The data should therefore be seen as the program directors' subjective perceptions. In addition, only 102 of the 210 programs who received the email with the request to respond to this web-based survey actually responded. While an approximately 50 percent response rate is acceptable for a national survey of this nature, it could be that program directors of dental hygiene programs without curriculum content for this topic might have been less likely to respond to this survey. However, this explanation might be only partly accurate because studies of response rates have shown that web-based surveys tend to have lower response rates than mailed questionnaires. ${ }^{12,13}$ Although web-based surveys are convenient to use, they might receive less attention and a lower likelihood of responses than surveys that are delivered by mail.

Given that new standards for dental hygiene programs concerning the treatment of patients with 
special needs were recently implemented, ${ }^{9}$ it seems crucial to consider how satisfied the program directors are with their own efforts in this area. While the average satisfaction with various aspects of their efforts is high as demonstrated by the data in Table 6, it is noteworthy that a number of program directors indicated that they are not satisfied with the status quo in their programs or provided neutral responses. While a direct assessment of the specific reasons for dissatisfaction might be difficult, it might be worthwhile to analyze the responses concerning the reported challenges shown in Table 5. Curriculum overload was most frequently chosen as a challenge by these respondents, and faculty expertise was identified as the least important challenge. It seems therefore that the program directors perceive that they have the faculty resources to optimally train their students in this area, but believe that they lack the time to actually include enough material about this matter.

Given that the majority of program directors reported that they do not perceive a lack of patients with special needs (see Table 5), one potential solution to the challenge of curriculum overload could be to include more patients with special needs in their regular patient pool, rather than treating patients with special needs as a distinct group. This strategy would provide students with enhanced opportunities to interact with these patients and their families during the already scheduled clinic times. This approach could provide students with more opportunities to assess the treatment needs of these patients as part of routine clinical education. Such an increase in exposing students to patients with special needs could be accomplished without expanding the curriculum, because students would spend the same amount of time in clinics as they currently do, but would learn more about special needs patients and their needs in these settings. Increasing the number of patients with special needs that students treat could also contribute to having students learn more about a wider variety of patient, family, and care provider concerns.

To this point in time, few studies have explored how dental hygiene students are prepared to manage patients with disabilities. Lemon and Reveal reported that only 17 percent of dental hygiene programs believed that the dental hygiene needs of the mentally ill were adequately addressed in their communities. ${ }^{14}$ In addition, students from 57 percent of responding programs did not provide oral care to mentally ill patients. While our study provides a baseline assessment of what dental hygiene programs in the United States include in their curricula concerning these issues, it is important to assess additional facets of this problem. Surveys of faculty members in dental hygiene programs could, for example, assess whether they perceive themselves well prepared to provide both patient care and instruction in the area of patients with special needs. Surveys of students could, for example, explore their perceptions of their educational experiences with the treatment of patients with special needs. While several studies have evaluated dental students' attitudes and confidence when treating patients with disabilities, more research is needed to understand the learning environment of dental hygiene students.

\section{Conclusions}

The following observations and recommendations are provided based on the findings from this survey-based study:

1. Nearly all U.S. dental hygiene programs include material about the treatment of patients with special needs during their classroom-based educational efforts, but less than 50 percent of programs require their students to gain clinical experiences with these patients.

2. It seems crucial to design a core curriculum for dental hygiene programs that includes material about the treatment of various kinds of patients with special needs. While many dental hygiene textbooks, such as the one by Wilkins, ${ }^{15}$ include substantial material about patients with special needs, other textbooks do not provide information about the same groups of patients under the heading "patients with special needs." It seems, therefore, essential to develop a shared understanding of the definition of "patients with special needs." At this point, patients with more common disabilities are likely to encounter providers who have been educated about their needs, while patients with other disabilities might be less fortunate.

3. An interdisciplinary approach to educating students about the treatment of these patients is currently used by a substantial number of programs and could be interpreted as a positive contributing factor to address the complexity of the issues involved when managing patients with special needs.

4. Given the reported challenges and the less than optimal satisfaction levels with several aspects of the current curricula, it seems worthwhile to consider how curricular resources could be 
developed on a national level to support dental hygiene programs in their teaching efforts in this domain.

\section{REFERENCES}

1. U.S. Census Bureau. Census 2000 brief: disability status. In: Summary file 3: 2000 census of population and housing. At: www.census.gov/prod/cen2000/doc/sf3.pdf. Accessed: April 19, 2008.

2. U.S. Department of Health and Human Services. Oral health in America: a report of the surgeon general. Rockville, MD: U.S. Department of Health and Human Services, National Institute of Dental and Craniofacial Research, National Institutes of Health, 2000.

3. Waldman HB, Perlman SP, Swerdloff M. Use of pediatric dental services in the 1990s: some continuing difficulties. J Dent Child 2000;67:59-63.

4. Feldman CA, Giniger M, Sanders M, Saporito R, Zohn HK, Perlman SP. Special Olympics, special smiles: assessing the feasibility of epidemiologic data collection. J Am Dent Assoc 1997;128:1687-96.

5. Dao LP, Zwetchkenbaum S, Inglehart MR. General dentists and special needs patients: does dental education matter? J Dent Educ 2005;69(10):1107-15.

6. Kinne RD, Stiefel DJ. Assessment of student attitude and confidence in a program of dental education in care of the disabled. J Dent Educ 1979;43(5):271-5.
7. Stoltenberg JL, Walker PO. Student dental hygienists' and dental hygiene educators' attitudes toward the handicapped. J Dent Hygiene 1989;63(3):117-23.

8. Bickley SR. Dental hygienists' attitudes toward dental care for people with a mental handicap and their perceptions of the adequacy of training. Br Dent J 1990;168(9):361-4.

9. Commission on Dental Accreditation. Accreditation standards for dental hygiene education programs. Chicago: American Dental Association, 1998.

10. SPSS Inc. SPSS 14.0 Student Version for Windows (SA). New York: Prentice Hall, 2006.

11. Chmar JE, Harlow AH, Weaver RG, Valachovic RW. Annual ADEA survey of dental school seniors, 2006 graduating class. J Dent Educ 2007;71(9):1228-53.

12. Leece P, Bhandari M, Sprague S, Swiontkowski MF, Schemitsch EH, Tornetta $\mathrm{P}$, et al. Internet versus mailed questionnaires: a controlled comparison (2). J Med Internet Res 2004;6:e39.

13. Couper MP, Blair J, Triplett T. A comparison of mail and email for a survey of employees in U.S. statistical agencies. J Official Statistics 1999;15:390-6.

14. Lemon S, Reveal M. Dental hygiene students' preparation for treatment of patients with mental illnesses. J Dent Educ 1991;55(11):724-8.

15. Wilkins EM. Clinical practice of the dental hygienist. 9th ed. Philadelphia: Lippincott Williams \& Wilkins, 2005. 